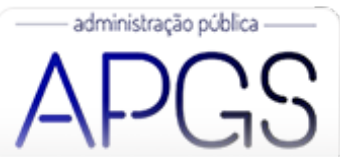

Administração Pública e Gestão Social ISSN: 2175-5787

apgs@ufv.br

Universidade Federal de Viçosa

Brasil

\title{
Divulgar para quê? Índice de disclosure e a importância atribuída por doadores e gestores à divulgação voluntária de informação
}

Pereira de Souza, Laísa Aparecida; Marcos Lima, Emanoel; de Oliveira Vendramin, Elisabeth; Pereira, Carlos Alberto

Divulgar para quê? Índice de disclosure e a importância atribuída por doadores e gestores à divulgação voluntária de informação

Administração Pública e Gestão Social, vol. 13, núm. 3, 2021

Universidade Federal de Viçosa, Brasil

Disponible en: https://www.redalyc.org/articulo.oa?id=351566982010 


\section{Divulgar para quê? Índice de disclosure e a importância atribuída por doadores e gestores à divulgação voluntária de informação}

Disclosure for what? Disclosure index and importance assigned by donors and managers to voluntary disclosure of information

¿Divulgar para qué? Índice de divulgación y la importancia asignada por donantes y gerentes a la divulgación voluntaria de información

Laisa Aparecida Pereira de Souza

Redalyc: https://www.redalyc.org/articulo.oa?

Universidade Federal de Mato Grosso do Sul, Brasil id $=351566982010$

laisa_ln@hotmail.com

Emanoel Marcos Lima

Universidade Federal de Mato Grosso do Sul, Brasil

emanoel.lima@ufms.br

Elisabeth de Oliveira Vendramin

Universidade Federal de Mato Grosso do Sul, Brasil

elisabeth.vendramin@ufms.br

Carlos Alberto Pereira

Universidade de São Paulo, Brasil

cap@usp.br

Recepción: 11 Agosto 2020

Aprobación: 16 Diciembre 2020

Publicación: 01 Julio 2021

\section{Resumo:}

Objetivo da pesquisa: Analisar se o índice de disclosure via website praticado por entidades sem fins lucrativos mostra-se alinhado à importância atribuída por doadores e gestores à divulgação voluntária de informações.

Enquadramento teórico: Teoria da Divulgação.

Metodologia: Foi construído um índice de disclosure (WDI) e aplicados questionários aos doadores e aos gestores das entidades do projeto Clique Esperança, de Campo Grande (MS), a fim de examinar a percepção desses dois grupos acerca da importância da divulgação de informações.

Resultados: Os achados evidenciam que o nível médio de divulgação de informações gerais é de $56,51 \%$, o de informações contábeis é de apenas 7,69\% e o de informações de desempenho é de 19,23\%, embora exista uma alta convergência entre as percepções de doadores e gestores sobre a importância dessas informações. Ainda, observou-se o alinhamento parcial entre essas percepções e os índices praticados, sendo alto o grau de alinhamento das informações gerais e baixo o grau de alinhamento de informações contábeis e desempenho.

Originalidade: Conciliação das percepções dos gestores e dos doadores sobre a importância da divulgação em websites.

Contribuições teóricas e práticas: Avanço das discussões sobre a otimização das práticas de divulgação de informações, como forma de reduzir a assimetria informacional, nas percepções de doadores e gestores.

Palavras-Chave: Terceiro Setor, Divulgação, Website, Prestação de Contas, Percepção.

\section{Abstract:}

Purpose of the research: The purpose of this research is to analyze whether the index of disclosure via the website practiced by non-profit entities is in line with the importance attributed by donors and managers to the voluntary disclosure of information. Theoretical framework: Theory of Disclosure. 
Methodology: A dissemination index (WDI) and questionnaires to donors and entities from the Clique Esperança project, in Campo Grande (capital of the state of Mato Grosso do Sul, in Brazil), were built in order to examine the perception of these two groups about the importance of information dissemination.

Results: The findings show that the average level of disclosure of general information is $56.51 \%$, the level of accounting information is only $7.69 \%$ and performance information is $19.23 \%$, although there is a high convergence between the perceptions of donors and managers about the importance of this information. Still, there was a partial alignment between these perceptions and indexes practiced, with a high degree of alignment of general information and a low degree of alignment of accounting information and performance.

Originality: Conciliation of the perceptions of managers and donors about the importance of disclosure on websites.

Theoretical and practical contributions: Addresses the interaction between donors/donations and entity/disclosure and also in the optimization of information dissemination practices, reducing information asymmetry.

KEYWORDS: Third Sector, Disclosure, Website, Accountability, Perception.

\section{RESUMEN:}

Objetivo de la investigación: Analizar si el índice de divulgación vía web que practican las entidades sin finalidad de lucro se ajusta a la importancia que los donantes y gestores atribuyen a la divulgación voluntaria de información.

Marco teórico: Teoría de la divulgación.

Metodología: Se crearon un índice de divulgación (WDI) y fue enviado encuestas para donantes y administradores de entidades del proyecto Clique Esperança, en Campo Grande (capital del estado de Mato Grosso do Sul, em Brasil), con la finalidad de examinar la percepción de estos dos grupos sobre la importancia de la divulgación de informaciones.

Resultados: Los resultados muestran que el nivel medio de divulgación de información general es 56,51\%, el nível de la información contable es solo 7,69\% y el de la información de desempeño es 19,23\%, pero existe una alta convergencia entre como percepciones de donantes y administradores sobre la importancia de estas informaciones. Además, existe un alineamiento parcial entre percepciones y los índices practicados, con un alto grado de alineamiento de la información general y un bajo grado de alineamiento de la información contable y desempeño. Originalidad: Conciliación de las percepciones de administradores y donantes sobre la importancia de la divulgación en la web.

Aportes teóricos y prácticos: Avances em las discusiones sobre la optimización de las prácticas de divulgación de información como forma de reducir la asimetría de información, em las percepciones de donantes y administradores.

Palabras Clave: Tercer Sector, Divulgación, Web, Responsabilidad, Percepción.

\section{INTRODUÇÃO}

O terceiro setor existe com o fito de abrandar os problemas de demandas sociais e é composto por entidades de iniciativa privada, mas sem finalidade de lucros, que trabalham visando à promoção do bem comum. Esse setor diferencia-se, assim, do primeiro setor, que, embora também tenha a incumbência de propiciar o bem coletivo, abrange organizações governamentais, e do segundo setor, que engloba organizações de iniciativa privada, mas com finalidade lucrativa (Cruz, 2010). Apesar de não possuírem finalidade lucrativa, as organizações do terceiro setor necessitam de recursos financeiros e por isso valem-se das mais variadas fontes de financiamento de suas atividades - transferências diretas e indiretas, crowdfunding, patrocínios e doações - para que, assim, mantenham-se perenes e cumpram sua missão outrora estabelecida.

À medida que as entidades disponibilizam mais informações sobre sua atuação e suprem as necessidades informacionais dos diversos interessados, mais propensas estão a receber doações de recursos financeiros (Deng, Lu, \& Huang, 2015; Saxton, Neely, \& Guo, 2014), ensejando a necessidade de uma gestão transparente e responsável, capaz de fidelizar atuais colaboradores, além de atrair novos.

O disclosure, então, pode ser considerado como um meio útil de accountability, pois, conforme defendem Lima e Pereira (2011), é através da prestação de contas que pode haver uma efetiva comunicação entre a entidade sem fins lucrativos e os diversos interessados em avaliar o seu desempenho, além de ser poderoso na redução da assimetria de informações existente entre a empresa e os stakeholders (Consoni, Colauto, \& Lima, 2017; Cruz, 2010; Lima \& Pereira, 2011). 
Dado o grande número de organizações do terceiro setor, infere-se que o doador precisa adotar algum critério para escolher a entidade a ser beneficiada, bem como a quantia a ser doada. Assim, a prática do disclosure mostra-se como uma estratégia de diferenciação para as organizações, pela qual poderão comunicarse com os potenciais doadores, a fim de atrair mais doações (Saxton \& Zhuang, 2013).

Partindo da premissa de que existe uma assimetria de informações considerável entre as instituições de caridade e os doadores, Saxton e Zhuang (2013, p. 42) estabelecem que uma questão fundamental norteia um dos lados da equação - o doador: “como posso decidir para onde doar meu dinheiro? E quanto devo doar?”, e, por outro lado, o dilema da entidade, tida como o outro lado da equação é: “quanto devo divulgar?” (Saxton \& Zhuang, 2013).

Verrecchia (1983) exemplifica essas questões ao propor um modelo buscando apresentar um equilíbrio na divulgação, em que a motivação dos gestores esteja em equilíbrio com a expectativa dos comerciantes.

Semelhantemente, na tentativa de compreender o processo de interação entre doação e divulgação, Saxton e Zhuang (2013) afirmam que a teoria da comunicação ou divulgação apresenta uma lacuna, visto que tem se concentrado em apenas um lado da equação, ou seja, ou no âmbito da entidade/divulgação ou no contexto de doadores/doações. Segundo os autores, essa abordagem não pode fornecer, com completude, uma explicação do processo de tomada de decisão. Desta forma, o fundamento para entender essa interação é o reconhecimento de que os doadores reagirão estrategicamente à divulgação com base em suas preferências individuais, e que as organizações tentarão incorporar antecipadamente essas preferências em suas decisões de divulgação (Saxton \& Zhuang, 2013).

Dessa forma, surge a seguinte questão de pesquisa: O índice de disclosure via website praticado por entidades sem fins lucrativos mostra-se alinhado com a importância atribuída por doadores e gestores à divulgação voluntária de informações?

Sabe-se que o disclosure pode se caracterizar como obrigatório ou voluntário, sendo obrigatório quando provém de normatizações e obrigações legais e voluntário se excedente àquilo que é exigido por lei e decorre da decisão discricionária da entidade.

Assim, com vistas a entender quais informações são preteridas por doadores, quais informações são tidas como importantes pelas entidades quando da divulgação e qual a correspondência dessas preferências no atual nível de disclosure das organizações sem fins lucrativos, o objetivo deste estudo é analisar se o índice de disclosure via website praticado por entidades sem fins lucrativos mostra-se alinhado à importância atribuída por doadores e gestores à divulgação voluntária de informações.

Conforme revisão sistemática da literatura realizada nas bases Science Direct e Scopus, para o período de 2009 a 2018, mediante utilização da string "((("disclosure" OR "divulgação") OR ("communication" OR "comunicação")) AND (("third sector" OR "terceiro setor") OR ("nonprofit" OR "sem fins lucrativos")) AND (("donations" OR "doações") OR ("donors" OR "doadores")))", pôde-se obter um resultado de 10 estudos cujo escopo era a análise da divulgação especificamente em websites ou construção de índices de disclosure. Contudo, dentre todos os achados que utilizaram a divulgação, disclosure ou índice de transparência como variável dependente ou explicada, nenhum examinou ou conciliou as percepçôes dos gestores e dos doadores sobre a importância da divulgação em websites, reforçando a importância deste estudo. Ainda, esta pesquisa colabora para a elaboração de futuros índices de disclosure, ponderados, dada a utilização das importâncias atribuídas por doadores e gestores a cada item de divulgação.

Este estudo contribui para a otimização das práticas de divulgação, pois, dado que os doadores expressaram quais informações acham mais importantes e são, portanto, preteridas, as entidades podem, a partir de então, concentrar seus esforços no fornecimento dessas informações, com vistas a diminuir a assimetria informacional. 


\section{FUNDAMENTOS TEÓRICOS}

\section{Teoria sobre Divulgação}

A divulgação é tida como um instrumento de comunicação entre as organizações e os participantes do mercado ou demais partes interessadas em sua atuação (Guidry \& Patten, 2012; Lima \& Pereira, 2011). Assim, embasa-se nas prerrogativas de que o disclosure é responsável pela redução de assimetria informacional entre as entidades - representadas por gerentes, gestores ou dirigentes —e os investidores (Lima, 2009; Parsons, 2007) e que maiores níveis de divulgação se associam a um menor custo de capital (Botosan, 2006). Ainda que existam controvérsias na literatura sobre esses benefícios, Botosan (2006) afirma que a maior parte dos estudos postulam as vantagens da divulgação.

Botosan (2006) enfatiza, ainda, a existência de duas correntes de pesquisa sobre as benesses da divulgação, uma corrente reduzindo o risco de estimativa dos investidores e outra reduzindo a assimetria de informações, visto que quanto menos informações disponíveis, mais altos são os riscos de estimações para os investidores e a assimetria de informações e, automaticamente, maior o custo de capital.

No âmbito do terceiro setor, os proveitos da divulgação subsistem. Além de reduzir a desigualdade de acesso a informações entre os gestores das entidades e os doadores, sendo possível esperar um maior volume de doações, melhora na tomada de decisões dos doadores, dado o acesso a informações tempestivas e relevantes (Parsons, 2007) e, ainda, promove maior transparência, suscitando maior confiança do público (Saxton, Kuo, \& Ho, 2012).

O disclosure pode caracterizar-se como obrigatório ou voluntário. É obrigatório quando provém de normatizações, obrigações legais ou relatórios regulamentados, com vistas a fornecer um nível mínimo de informações aos usuários, e é voluntário se for decorrente da decisão discricionária das organizações, com base no interesse observado, e exceder aquilo que é exigido por lei (Healy \& Palepu, 2001).

Para Lima (2009), as entidades sem fins lucrativos, geralmente, atêm-se à prática do disclosure obrigatório, limitando a divulgação às obrigações legais, mas salienta a importância da divulgação completa de informações, até mesmo daquelas negativas para a entidade, pois, conforme o autor, quando bem fundamentadas, estas também fornecem mais segurança aos investidores, ou doadores, no caso de entidades sem fins lucrativos.

Dye (2001), em uma crítica ao estudo de Verrecchia (2001), afirma que um leitor, quando acessa o "Essays on disclosure", produzido por Verrecchia, depreende que a literatura não está amadurecida e não é unificada o suficiente para se consolidar como teoria, e concorda em partes com tal afirmação. Para Dye (2001), tratandose de disclosure obrigatório na contabilidade, não há uma teoria estabelecida, haja vista a escassez de pesquisas sobre o tema, sendo uma lacuna a ser preenchida pelos pesquisadores.

Contudo, existe uma teoria consolidada da divulgação voluntária (Dye, 2001). Para o referido autor, a teoria da divulgação voluntária é um desdobramento que pode ser estudado dentro da teoria dos jogos, partindo da premissa de que a entidade tende a divulgar informações que sejam favoráveis e aumentem o valor de mercado de suas ações, podendo suprimir informações desfavoráveis para o valor da empresa.

Para Verrecchia (2001), a pesquisa sobre a divulgação estrutura-se em três categorias, que são: divulgação baseada na associação (association-based disclosure), divulgação baseada na discricionariedade (discretionarybased disclosure) e divulgação baseada na eficiência (efficiency-based disclosure).

A primeira categoria, referente à divulgação baseada na associação, tem foco no processo de divulgação exógeno, e sugere uma associação entre o disclosure e seus efeitos nas atividades dos investidores (Verrecchia, 2001).

A segunda, sobre divulgação baseada na discricionariedade, com foco endógeno, conforme aponta Verrecchia (2001), estuda o poder discricionário que os gestores exercem, decidindo se vão divulgar ou não as informações às quais têm acesso, bem como quais as motivações e incentivos para tal feito. Essa abordagem 
leva o gestor a um julgamento, de modo que considere os custos e os benefícios da divulgação de informações sobre a empresa. Dye (2001) defende que a entidade divulgará informações favoráveis e reterá aquelas não favoráveis, dado que, se a empresa não divulgar determinada informação, o próprio mercado interpretará essa informação como ruim.

Segundo Salotti e Yamamoto (2005), interpretar uma informação não divulgada como ruim é um problema intitulado de seleção adversa, em que os investidores descontam da estimativa do valor do ativo alguma quantia, quando uma informação não é divulgada. Por isso, esse assunto é muito pertinente quando se trata das pesquisas enquadradas na categoria de divulgação baseada na discricionariedade.

Partindo para a terceira categoria de pesquisa da taxonomia proposta por Verrecchia (2001), tem-se a divulgação baseada na eficiência, caracterizada como ex ante por Salotti e Yamamoto (2005), em que se estudam as preferências dadas ao conjunto de divulgação, assumindo que as informações ainda não foram divulgadas.

Tratando da divulgação baseada na eficiência, Verrecchia (2001) expõe a necessidade da existência de uma análise do volume de informações que a empresa divulgará. Essa análise acontece antes que a informação seja disseminada, justamente para que a divulgação ao mercado ocorra em um volume necessário para maximizar a relação custo versus benefício. Salotti e Yamamoto (2005, p. 68) reiteram a relação custo benefício na divulgação baseada na eficiência, rememorando a Teoria dos Jogos, ao defenderem que as pesquisas desse tipo "avaliam quais os tipos de divulgação mais eficientes, sendo as ações dos investidores endógenas. Neste caso, o jogo se concentra em ambos os jogadores, pois procura-se avaliar a solução ótima para ambos”. Assim, observa-se que o presente estudo abrange essas três categorias de pesquisa propostas por Verrechia (2001).

\section{Divulgação Voluntária de Informações na Web}

Lee e Blouin (2017) postulam que o primeiro passo para se adotar uma inovação é que os gestores das entidades tenham consciência de sua importância, ou seja, a divulgação na web exige conhecimento, por parte destes, das benesses inerentes a essa prática, pois quando os gestores mantêm uma atitude favorável e acreditam que o disclosure via website é uma ferramenta relevante para promover a transparência e responsabilidade, eles influenciam positivamente a organização a adotar a divulgação voluntária na internet.

Dada a ampla difusão do uso da internet, por meio de sites, blogs ou mídias sociais, o fornecimento e divulgação de informações organizacionais foi ampliado e tornou-se mais fácil. É nesse espaço que os potenciais doadores podem ter acesso a informações básicas sobre as entidades, informações financeiras e de desempenho, bem como a eficiência e eficácia alcançada por uma entidade. Assim, pode-se concluir que a divulgação na web facilita a disseminação de informações relevantes para vários stakeholders, fornecendo informações úteis, principalmente aos doadores, que estão dispostos a pagar pela divulgação de informações de qualidade nos sites das entidades sem fins lucrativos, aumentando o volume de doações (Saxton et al., 2014).

Saxton, Neely e Guo (2014) sintetizam as principais razóes pelas quais as entidades deveriam adotar a divulgação na web, sendo elas: a) popularização e democratização da informação gerada pela difusão de novas mídias; b) dado que a natureza da divulgação voluntária consiste na inexigibilidade de que as organizações sem fins lucrativos publiquem informaçóes financeiras ou de desempenho em seus sites, isso se mostra como uma oportunidade para evidenciar a eficácia da divulgação; e c) divulgação na web mostra-se como um sinal de prestação de contas aos contribuintes, transmitindo informações particularmente valiosas para os doadores.

Corroborando com essa perspectiva, Lee e Blouin (2017) enfatizam que a sobrevivência das organizações não-governamentais depende em grande parte do fortalecimento da confiança pública através da divulgação de resultados financeiros e de desempenho de alta qualidade, reforçando a importância dos websites como um meio para disseminação de informações. 
Apesar de todos os benefícios da divulgação, alguns autores apontam desafios para adoção ou motivos para não adoção da prática do disclosure. A exemplo, a ideia de que os custos de se fazer uma divulgação são fixados independentemente do que é divulgado é questionável, pois, na maioria das vezes, os custos de divulgação variam de acordo com a quantidade de informações divulgadas (Dye, 2001). Lee e Blouin (2017) também citam, em seu estudo, alguns motivos para a não adoção da divulgação na web, baseados em estudos realizados, tais como a não percepção, por parte das entidades, dos benefícios decorrentes dessa divulgação e a restrição orçamentária, financeira e tecnológica das organizações, traduzindo a falta de prontidão organizacional.

Além disso, vale destacar que, se os custos para se divulgar não resultarem na disseminação de informações eficientes, que trarão um benefício monetário à entidade, essa carga de informações estará, potencialmente, desviando recursos da causa ou missão da organização.

\section{PROCEDIMENTOS METODOLÓGICOS}

Com o intuito de alcançar o objetivo proposto, foi realizada uma pesquisa descritiva e exploratória, com abordagem qualitativa, por apresentar-se mais apropriada, conforme defendem Collis e Hussey (2005), pois o trabalho possui o fito de analisar se o índice de disclosure via website praticado por entidades sem fins lucrativos mostra-se alinhado com a importância atribuída por doadores e gestores à divulgação voluntária de informações, permitindo a exposição da realidade múltipla vista pelos participantes do estudo, comparando essas percepções ao nível de divulgação adotado pelas entidades da amostra. Ainda, esta pesquisa se classifica como bibliográfica e documental, pois valeu-se da revisão da literatura, da utilização de demonstrativos contábeis e relatórios financeiros e não financeiros, tais como prestação de contas e cartilhas de atendimentos realizados.

A população da pesquisa foi composta por 64 entidades do terceiro setor, participantes do projeto "Clique Esperança” (conforme o site do projeto em julho de 2019). Este projeto é vinculado ao Fundo Municipal para a Infância e a Adolescência (FMIA) de Campo Grande (MS) e trabalha na promoção da defesa dos direitos das crianças e do adolescente, servindo como meio para que pessoas físicas ou jurídicas realizem doações ao próprio fundo ou escolha a qual entidade, dentre as credenciadas no site do projeto, sua doação será destinada, obtendo benefícios como a restituição ou diminuição do Imposto de Renda a pagar.

Contudo, foram desconsideradas para a elaboração do índice de divulgação via website 38 entidades: 24 porque os respectivos websites não foram encontrados; 5 porque, embora tenham sites, estes são de um grupo de organizações que atuam nacionalmente, não sendo possível identificar o nível de disclosure de cada organização individualmente; 5 entidades porque os sites apresentavam erro ou problema de acesso; e 4 por não trabalharem especificamente com crianças ou adolescentes, apesar de estarem aptas no projeto, contrariando a legislação do FMIA.

Para a coleta dos dados referentes à mensuração do nível de evidenciação das entidades objeto do estudo, foi construído o Índice de Divulgação via Website - WDI -, utilizando um checklist contendo 20 itens, sendo 13 referentes às Informações Gerais (IG) da entidade, adaptados do trabalho de Gandía (2011) e Waters (2007); 5 itens sobre Informações Contábeis (IC), elaborados a partir da Norma Técnica NBC TG 26 (R5) - Apresentação das Demonstrações Contábeis (2017) e da ITG 2002 (R1) - Entidade sem Finalidade de Lucros (2015), os quais são de elaboração obrigatória e divulgação voluntária pelas entidades analisadas neste estudo; e dois relativos a Informações de Desempenho (ID), adaptados de Lima e Pereira (2011). Essas informações foram retiradas dos sites de cada organização em julho de 2019, sendo que para cada item divulgado foi atribuída a pontuação um (1), e se não divulgado, zero (0). Este índice apresenta limitações quanto à quantidade de itens de divulgação e à ausência de ponderações para os mesmos, tendo em vista que foi elaborado a partir da realidade das entidades do terceiro setor especificamente enquadradas na amostra deste estudo. 
Dado que as empresas integrantes da amostra deste estudo não têm obrigatoriedade de divulgar em website qualquer informação, mas prestar contas ao FMIA apenas do Projeto que será executado com os recursos recebidos, conforme Deliberação n. 345/CMDCA/2013, todos os itens do índice são considerados como disclosure voluntário.

No que tange à coleta de dados entre doadores, foram coletados dados entre os que doam especificamente via Clique Esperança, mediante a aplicação de um questionário, elaborado e operacionalizado via Google Forms. O instrumento de coleta foi pré-testado, usando uma pequena amostra de conveniência para garantir a adequabilidade e o arranjo lógico das questões.

O questionário continha quatro seções. Na primeira seção, foi disponibilizado o Termo de Consentimento Livre e Esclarecido (TCLE), no qual o doador foi convidado para participar da pesquisa e, somente em caso de aceite e concordância em participar como voluntário da pesquisa, é que podia prosseguir com o preenchimento do questionário. A segunda seção compôs-se de questões de múltipla escolha, visando verificar se o perfil do respondente se enquadra na delimitação do estudo. Já a terceira seção, com utilização da escala Likert, continha itens de divulgação em websites e o doador expressava a importância atribuída por ele à divulgação dos itens elencados. Por fim, a quarta seção abrangia itens de disclosure, mas com enfoque na divulgação em redes sociais. O link para acesso ao questionário foi amplamente divulgado nas redes sociais dos pesquisadores em modo público, para que outros compartilhassem o link em seus perfis, além de disponibilizados a escritórios de contabilidade da região, para que fossem encaminhados a seus clientes.

O total de doadores/doações ao Clique Esperança em 2018 foi de 239, sendo 229 pessoas físicas e 10 pessoas jurídicas, conforme Quadro Demonstrativo de Quantidade de Doações ao FMIA, fornecido pela Secretaria Municipal de Assistência Social de Campo Grande (MS). Esta pesquisa atingiu o total de 34 doadores pessoas físicas, mas foram consideradas apenas 26 respostas, pois uma questão estratégica foi incluída no questionário a fim de filtrar aqueles que realizaram doações, especificamente, via Clique Esperança, o que representa, aproximadamente, $11 \%$ da população, sendo esta amostra significativa a um nível de confiança de $85 \%$.

Também foram aplicados questionários aos dirigentes responsáveis pelas 64 instituições aptas no Clique Esperança, independentemente de a entidade possuir ou não um website, utilizando o Google Forms e seguindo a mesma estrutura do instrumento de coleta utilizado para com os doadores, porém, com uma seção a mais, onde os gestores responderam a duas questões abertas explanando sobre os benefícios obtidos ou esperados com a divulgação e sobre os obstáculos para adoção de tal prática. O link para acesso aos questionários foi enviado em agosto de 2019 e reenviado em setembro de 2019 aos endereços de e-mail dessas entidades, cabendo destacar que estes e-mails são públicos e disponibilizados no próprio site do Clique Esperança. Houve um total de 14 respostas, sendo 13 válidas, pois 1 dos respondentes não concordou com o TCLE.

Os questionários foram estruturados de forma a captar a percepção dos respondentes em relação ao grau de importância atribuída à divulgação via websites dos itens do checklist, como pode-se observar no Quadro 1:

Quadro 1 - Pontuação da Pesquisa Atribuída pelos Doadores e Gestores

$\begin{array}{ll}\text { Escala } & \text { Indicadores } \\ 0 & \text { Sem importância, näo deve ser divulgado } \\ 1 & \text { Pouca importância, deve ser divulgado } \\ 2 & \begin{array}{l}\text { Importância moderada, deve ser } \\ \text { divulgado }\end{array} \\ 3 & \text { Extremamente importante, deve ser } \\ \text { divulgado }\end{array}$

Ainda, como etapa final de coleta de dados nas entidades, foram realizadas entrevistas em dezembro de 2019, com duração de 21 e 23 minutos, com duas organizações: uma possui website e a outra não, sendo estas 
selecionadas por conveniência e disponibilidade de participação. Assim, foi possível investigar com maior detalhamento quais os motivos para a não divulgação ou retenção de informações, bem como as dificuldades para a prática da divulgação em websites.

Os dados dos questionários foram apresentados e analisados, mediante a utilização de estatística descritiva, além do cunho interpretativo, especialmente nas questões abertas e entrevistas, pois conforme Creswell (2007, p. 186), "a pesquisa qualitativa é fundamentalmente interpretativa”, já que são realizadas descrições do cenário de divulgação das entidades sem fins lucrativos, e então análises são feitas, por meio da exploração das percepções dos grupos abrangidos neste trabalho - doadores e entidades - propiciando a interpretação dos dados, amparada pela teoria.

\section{APRESENTAÇÃOE DISCUSSÃO DOS RESULTADOS}

\section{Comparação entre o Disclosure Praticado pelas Entidades Integrantes do Clique Esperança e a Importância Atribuída pelos Respondentes à Divulgação de Informações}

Com a intenção de identificar o nível de divulgação das entidades analisadas, foi construído, inicialmente, um índice de divulgação via website para cada uma das organizações integrantes da amostra, posto que, similarmente ao mundo corporativo, é desejável que as entidades do terceiro setor utilizem a web para divulgar informações voluntárias, pois, conforme Lee e Blouin (2017), esse é um processo significativo para a construção de transparência e responsabilidade, já que as práticas de divulgação tradicionais e o fornecimento de informações apenas quando requerido pode apresentar-se como um impedimento à prestação de contas.

Doadores e gestores foram inquiridos, entre outros pontos, acerca da importância da divulgação dos itens do checklist, nos websites e os resultados estão sintetizados na Tabela 1:

Tabela 1 - Comparativo entre o Nível de Disclosure de Informações Gerais e o Grau de Importância Atribuídos pelos Doadores e Gestores à Divulgação

\begin{tabular}{|c|c|c|c|c|c|c|c|c|c|}
\hline & & DOADORES & & & & GESTORES & & & \\
\hline 2. Histórico da Entidade & $76,92 \%$ & $50,00 \%$ & $42,31 \%$ & $7,69 \%$ & $0,00 \%$ & $0,00 \%$ & $0,00 \%$ & $23,08 \%$ & $76,92 \%$ \\
\hline 3. Missão & $53,85 \%$ & $34,62 \%$ & $46,15 \%$ & $19,23 \%$ & $0,00 \%$ & $0,00 \%$ & $0,00 \%$ & $0,00 \%$ & $100,00 \%$ \\
\hline 6. Espaço Notícias & $53,85 \%$ & $50,00 \%$ & $34,62 \%$ & $15,38 \%$ & $0,00 \%$ & $0,00 \%$ & $0,00 \%$ & $15,38 \%$ & $84,62 \%$ \\
\hline 7. Localizaçäo & $96,15 \%$ & $34,62 \%$ & $30,77 \%$ & $30,77 \%$ & $3,85 \%$ & $0,00 \%$ & $0,00 \%$ & $15,38 \%$ & $84,62 \%$ \\
\hline 8. Contato & $96,15 \%$ & $50,00 \%$ & $38,46 \%$ & $11,54 \%$ & $0,00 \%$ & $0,00 \%$ & $0,00 \%$ & $15,38 \%$ & $84,62 \%$ \\
\hline 9. No Func. Contratados & $3,85 \%$ & $23,08 \%$ & $53,85 \%$ & $23,08 \%$ & $0,00 \%$ & $23,08 \%$ & $15,38 \%$ & $38,46 \%$ & $23,08 \%$ \\
\hline 10. $\mathrm{N}^{\circ}$ Voluntários & $11,54 \%$ & $26,92 \%$ & $46,15 \%$ & $26,92 \%$ & $0,00 \%$ & $15,38 \%$ & $7,69 \%$ & $30,77 \%$ & $46,15 \%$ \\
\hline Divulgação Média & $56,51 \%$ & & & & & & & & \\
\hline
\end{tabular}

Uma informação importante, previamente levantada na segunda seção do questionário, foi o fato de que $57,7 \%$ dos doadores nem sempre procuram e visitam o website da entidade às quais pretendem doar, e um 
número ainda maior - $61,5 \%$ ou 16 respondentes - não acessam as redes sociais das entidades sem fins lucrativos às quais pretendem doar. Contudo, mesmo assim, acham relevante que as entidades mantenham um website e divulguem informações nele, evidenciando que os doadores valorizam a simples presença na internet.

Constata-se, pela observação da Tabela 1, que tanto doadores quanto entidades, estas representadas por seus gestores, consideram importante a divulgação de informações gerais nos websites das organizações. Embora o grau de importância varie, a classificação dos itens em "Pouca Importância", "Importância Moderada" ou "Importância Extrema" implica na necessidade de divulgação do item, sendo que apenas os respondentes que assinalaram a opção "Sem Importância" não acham relevante e, por conseguinte, dispensam a divulgação da informação. Assim sendo, pode-se afirmar que não existe unanimidade quanto à importância da prática de disclosure de cinco dos treze itens componentes do grupo de Informações Gerais, visto que, para 3,85\% dos doadores, divulgar o campo de atuação, a localização e o link para acesso às redes sociais é dispensável, e para os gestores, é sem importância e não deve ser divulgado o número de funcionários contratados e o número de voluntários.

Quanto aos demais itens, tais como visão, missão, valores, campo de atuação, espaço para divulgação de notícias, entre outros, tanto os doadores quanto as entidades consideram relevante que sejam divulgados, o que se confirma com a afirmação de Gandía (2011), de que a divulgação desses itens gerais reflete o desejo da organização em estar presente na internet, mantendo um relacionamento com a sociedade acerca dos projetos que estão sendo desenvolvidos, bem como acerca da gestão dos recursos financeiros.

Apresenta-se também, na Tabela 1, o nível médio de cada item de disclosure praticado pelas entidades integrantes da amostra pesquisada, conforme metodologia adotada e já exposta neste trabalho para a construção do WDI, além da apresentação no nível médio de divulgação da categoria, perfazendo o total de 56,51\%, semelhante aos resultados apresentados por Gandía (2011), onde esta categoria de informações também apresentou maior nível de disclosure. Comparativamente são apresentadas as percepções dos doadores e gestores, captadas mediante aplicação de questionário, acerca do grau de importância e relevância da divulgação dos itens do índice. Cabe ainda salientar que, embora os respondentes devessem optar por graus diferentes de importância, apenas a opção "Sem Importância" implicava na dispensação da divulgação do item.

Observa-se do Tabela 1, que, ressalvados os itens 1,7,9,10 e 13, todos os outros itens apresentam consenso entre os respondentes acerca da importância da divulgação via website. Não obstante, existem itens com baixo percentual de divulgação pelas entidades, como, por exemplo, missão, visão e valores, se comparados com a percepção dos doadores e dos gestores acerca de sua relevância. Apenas 23,08\% das entidades declaram em seus websites quais são os valores da organização, mas mais de $80 \%$ dos doadores atribuíram a essa informação importância extrema ou moderada e $100 \%$ dos gestores a consideram extremamente útil.

Cabe enfatizar que o item 1 (Campo de Atuação) e o item 7 (Localização) foram considerados sem importância por uma parcela pequena $(3,85 \%)$ de doadores e, comparativamente, tais itens tiveram uma média de divulgação de $96,15 \%$. Ainda, percebe-se que 23,08\% e $15,38 \%$ das entidades não consideram importante divulgar o número de funcionários contratados e o número de voluntários, respectivamente, e os níveis médios de disclosure desses itens são os mais baixos da categoria, juntamente com a disponibilização de um espaço para dúvidas, sugestões ou reclamações (Ouvidoria), com a diferença de que esta última é considerada importante para se divulgar tanto pelos doadores quanto pelos gestores.

Por fim, destaca-se que apenas a divulgação de fotos ou vídeos nos websites exprimiu integral correspondência entre o que é divulgado atualmente pelas entidades e o que é considerado relevante para os inquiridos. 
Tabela 2 - Comparativo entre o Nível de Disclosure de Informações Contábeis e o Grau de Importância Atribuídos pelos Doadores e Gestores à Divulgação

\begin{tabular}{|c|c|c|c|c|c|c|c|c|c|}
\hline & & DOADORES & & & & GESTORES & & & \\
\hline & WDI & $\begin{array}{l}\text { Importância } \\
\text { Extrema }\end{array}$ & $\begin{array}{l}\text { Importância } \\
\text { Moderada }\end{array}$ & Pouca Importância & Sem Importância & Sem Importância & Pouca Importância & $\begin{array}{l}\text { Importância } \\
\text { Moderada }\end{array}$ & Importância Extrema \\
\hline 14. Balanço Patrimonial & $7,69 \%$ & $46,15 \%$ & $23,08 \%$ & $30,77 \%$ & $0,00 \%$ & $7,69 \%$ & $0,00 \%$ & $23,08 \%$ & $69,23 \%$ \\
\hline $\begin{array}{l}\text { 15. Dem. Resultado } \\
\text { Exercicio }\end{array}$ & $7,69 \%$ & $53,85 \%$ & $23,08 \%$ & $23,08 \%$ & $0,00 \%$ & $7,69 \%$ & $7,69 \%$ & $23,08 \%$ & $61,54 \%$ \\
\hline $\begin{array}{l}\text { 16. Dem. Mutaçōes } \\
\text { Patrimônio Liquido }\end{array}$ & $7,69 \%$ & $42,31 \%$ & $26,92 \%$ & $19,23 \%$ & $11,54 \%$ & $15,38 \%$ & $0,00 \%$ & $30,77 \%$ & $53,85 \%$ \\
\hline 17. Dem. Fluzos Caiza & $7,69 \%$ & $46,15 \%$ & $34,62 \%$ & $19,23 \%$ & $0,00 \%$ & $15,38 \%$ & $7,69 \%$ & $46,15 \%$ & $30,77 \%$ \\
\hline 18. Notas Explicativas & $7,69 \%$ & $50 \%$ & $26,92 \%$ & $19,23 \%$ & $3,85 \%$ & $15,38 \%$ & $7,69 \%$ & $23,08 \%$ & $53,85 \%$ \\
\hline Divulgaçăo Média & $7,69 \%$ & & & & & & & & \\
\hline
\end{tabular}

Já no que está relacionado à divulgação de informações contábeis, nota-se, pela observação da Tabela 2, que essa categoria de informações foi a que apresentou a menor média de evidenciação $(7,69 \%)$, percentual bem menor que o encontrado por Haski-Leventhal e Foot (2016), que foi de 50,69\%. Apenas 2 entidades da amostra divulgaram as informações contábeis, cabendo salientar que foi considerado como critério para esse grupo as demonstrações relativas ao ano de 2018. Porém, embora pouco divulgados, os demonstrativos contábeis foram elencados como importantes e meritórios de divulgação por quase $100 \%$ dos doadores, excetuando a Demonstração das Mutações do Patrimônio Líquido, que foi considerada sem importância por $11,54 \%$ dos doadores e as Notas explicativas, consideradas dispensáveis de divulgação por apenas 3,85\% dos doadores.

Nota-se ainda que, com relação às suas percepções de importância da divulgação de informações contábeis, os gestores não responderam em total concordância com os doadores ao questionário, visto que, em suas percepções, 7,69\% dos gestores consideram ser de pouco impacto a divulgação do Balanço Patrimonial e da Demonstração do Resultado do Exercício, e 15,38\% dispensam a divulgação dos demais demonstrativos. Apesar dessas divergências entre percepções, é notável que é baixo o desalinhamento entre o que os doadores esperam de informações e o que os gestores acham relevante para fins de divulgação, pois, em linhas gerais, a maioria dos respondentes desejam que informações contábeis estejam disponíveis nos websites das entidades, assim como também acontece com o grupo de informações gerais.

Tabela 3 - Comparativo entre o Nível de Disclosure de Informações de Desempenho e o Grau de Importância Atribuídos pelos Doadores e Gestores à Divulgação

\begin{tabular}{|c|c|c|c|c|c|c|c|c|c|}
\hline & \multirow[b]{2}{*}{ WDI } & \multicolumn{4}{|l|}{ DOADORES } & \multicolumn{4}{|l|}{ GESTORES } \\
\hline & & $\begin{array}{l}\text { Importância } \\
\text { Extrema }\end{array}$ & $\begin{array}{l}\text { Importância } \\
\text { Moderada }\end{array}$ & $\begin{array}{l}\text { Pouca } \\
\text { Importância }\end{array}$ & Sem Importância & Sem Importância & Pouca Importância & $\begin{array}{l}\text { Importância } \\
\text { Moderada }\end{array}$ & $\begin{array}{l}\text { Importância } \\
\text { Extrema }\end{array}$ \\
\hline $\begin{array}{l}\text { 19. Quantidade Pessoas } \\
\text { Assistidas }\end{array}$ & $38,46 \%$ & $84,62 \%$ & $11,54 \%$ & $3,85 \%$ & $0,00 \%$ & $7,69 \%$ & $0,00 \%$ & $7,69 \%$ & $84,62 \%$ \\
\hline $\begin{array}{l}\text { 20. Custo por Pessoa } \\
\text { Assistida }\end{array}$ & $0,00 \%$ & $76,92 \%$ & $19,23 \%$ & $3,85 \%$ & $0,00 \%$ & $7,69 \%$ & $0,00 \%$ & $30,77 \%$ & $61,54 \%$ \\
\hline Divulgaçäo Média & $19,23 \%$ & & & & & & & & \\
\hline
\end{tabular}

A categoria de informações de desempenho, composta por apenas dois itens, apresentou 38,46\% de divulgação média no item 19 (Quantidade de Pessoas Assistidas) que, de acordo com Lima (2009), revela o desempenho de serviços; e nenhuma divulgação para o item 20, que reflete o desempenho financeiro. Saxton et al. (2014) e Haski-Leventhal e Foot (2016) também construíram índices de divulgação abarcando itens de desempenho, contudo, cabe rememorar que, para consecução deste trabalho, foram selecionados de Lima (2009) esses dois itens, os quais, embora sejam poucos, seguem a proporcionalidade aproximada trazida por Haski-Leventhal e Foot (2016), por exemplo que, de 163 atributos do índice total, 24 eram de desempenho. 
Valendo-se do achado trazido por Saxton et al. (2014) de que existe uma correlação positiva e significativa entre as contribuições e divulgação total e de desempenho a um nível de confiança de 0,05, pode-se depreender que as entidades vinculadas ao Clique Esperança privam-se de receber mais contribuições pela baixa divulgação de informações de desempenho em seus websites. Outrossim, cabe focalizar que, para o doador, tanto a divulgação do quantitativo de assistidos quanto o custo de cada assistido são de extrema importância para 84,62\% e 76,92 dos doadores respondentes, respectivamente, como também para 84,62\% e 61,54\% das entidades. Contudo, a divulgação ainda é deficitária e até inexistente, como é o caso do item 20, comparativamente ao considerado importante para os doadores gestores.

Por fim, como pode-se verificar na Tabela 3, todos os doadores reconheceram a importância da divulgação das informações de desempenho. Contudo, 7,69\% dos gestores respondentes optaram pela não divulgação da quantidade de pessoas assistidas e o custo por pessoa assistida.

Dadas as análises anteriores e a contraposição com a teoria já apresentada nesta pesquisa, os resultados sugerem que os doadores, embora nem sempre acessem o site da entidade para a qual vão fazer uma doação, acham significativo que a entidade mantenha um website e divulgue os itens apresentados anteriormente, o que pode sinalizar que a divulgação na web é uma prática que suscita confiança de terceiros na instituição.

É notável salientar que praticamente todos os itens foram considerados elegíveis e importantes para divulgação por mais de $90 \%$ dos doadores e gestores. Com exceção do item 9 - número de funcionários contratados, e do item 10 - número de voluntários, que foram dispensados de divulgação por 23,08\% e $15,38 \%$ dos gestores, respectivamente, além de algumas informações contábeis, que foram consideradas sem importância. É exemplo a Demonstração das Mutações do Patrimônio Líquido, considerada sem importância por $11,54 \%$ dos doadores e $15,38 \%$ dos gestores, além da Demonstração dos Fluxos de Caixa, a qual nenhum doador considerou sem importância, mas foi considerada sem importância para 15,38\% dos gestores, e as Notas Explicativas, consideradas sem importância para 3,85\% dos doadores e para 15,38\% das entidades, cabendo lembrar que, de acordo com as normas contábeis brasileiras em vigor, as notas explicativas constituem parte das demonstrações contábeis.

Um resultado eminente é o fato de que não houve nenhum item dispensado ou considerado sem importância por percentual significativo de respondentes. Apesar disso, nota-se, pela observação das Tabelas 1, 2 e 3, que parte considerável dos itens são pouco divulgados pelas entidades.

Ressalvados alguns itens pontuais, conforme já explanado, tanto os doadores quanto os gestores posicionaram-se favoráveis à divulgação via website. Contudo, as organizações não praticaram full disclosure, suscitando a necessidade de se conhecer quais os motivos para a não divulgação de informações pelas entidades, visto que, pela percepção dos gestores inquiridos, a prática da divulgação é importante, e essa consciência, segundo Lee e Blouin (2017), seria o primeiro passo para que uma entidade adotasse uma prática inovadora. Por isso, os gestores também foram interrogados em relação aos obstáculos e desafios percebidos para a adoção da divulgação via website, porquanto já haviam sido levantados os níveis de divulgação de cada entidade e estes mostravam debilidade. 
Figura 1 - Desafios e Obstáculos para a Prática do Disclosure via Website

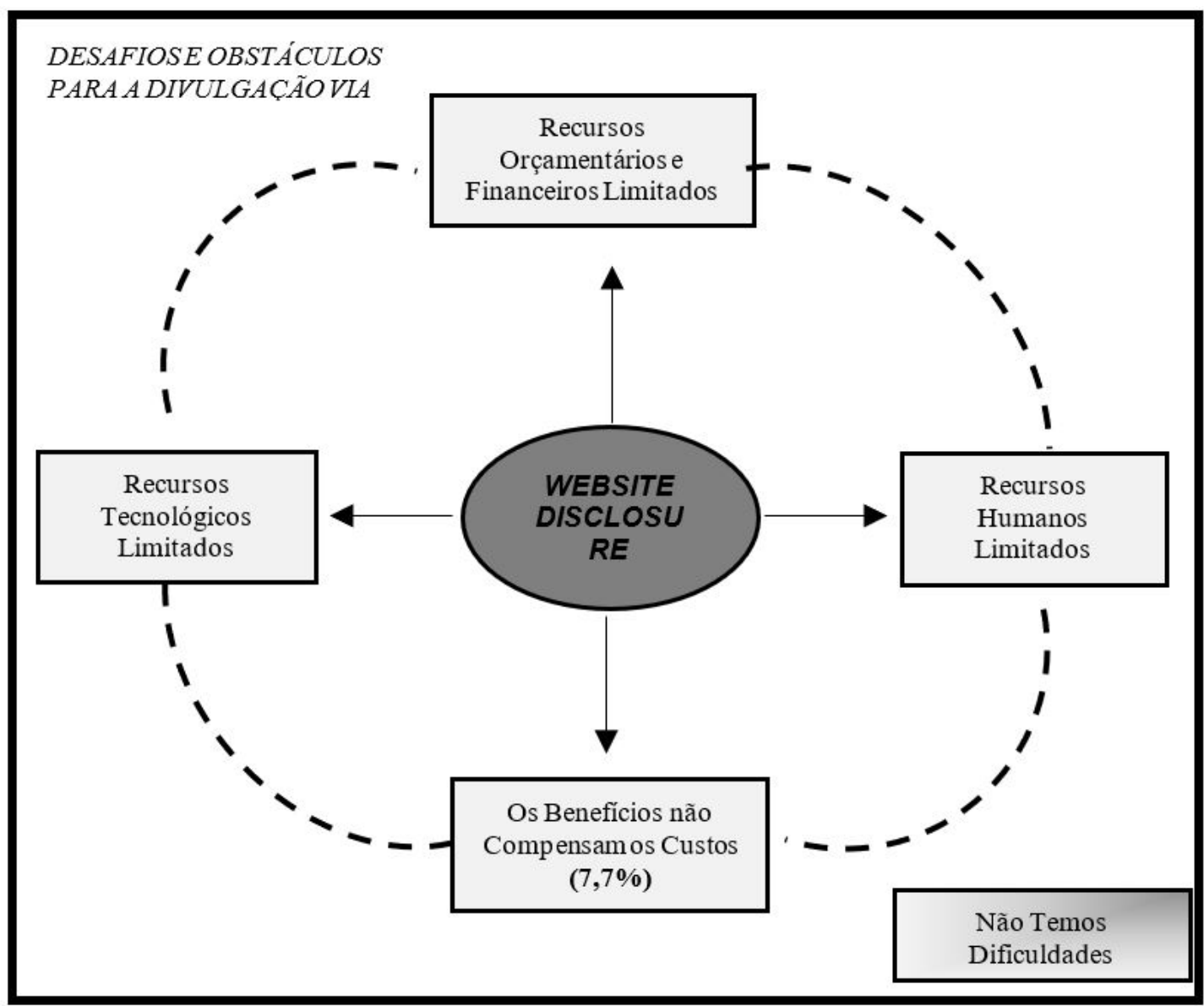

Nota-se que $61,5 \%$ dos inquiridos atestaram que restrição financeira e orçamentária é um obstáculo para a prática do disclosure. Embora tenha sido apresentado na literatura que a divulgação em websites possui um baixo custo, existem custos associados à divulgação (Salotti \& Yamamoto, 2005). Em decorrência disso, faz-se necessário balancear se os benefícios decorrentes dessa prática compensam os custos, e são os gestores, como tomadores de decisões, que fazem esse julgamento, conforme propõe a taxonomia de Verrecchia (2001).

Apenas $7,7 \%$ dos respondentes afirmaram que os benefícios da divulgação não compensam os custos e, por isso, pode-se inferir que a falta de recursos é um obstáculo eminente para o disclosure nas organizações sem fins lucrativos pesquisadas, visto que reconhecem os benefícios associados à tal prática. Este achado corrobora com o apresentado por Lee e Blouin (2017), no qual a hipótese de que prontidáo financeira, medida pela percepção dos gestores acerca da disponibilidade orçamentária da entidade associa-se a mais divulgação online.

Além disso, a limitação com recursos tecnológicos e a quantidade restrita de recursos humanos também foram tópicos pontuados pelos gestores como desafio e obstáculo para a divulgação via website.

\section{Visão dos Gestores Acerca da Importância da Divulgação de Informações}

Intentando fornecer robustez aos resultados encontrados com a aplicação do questionário, foram realizadas entrevistas. Pode-se perceber o interesse das entidades entrevistadas na pesquisa e em seu conteúdo, visto que se mostraram receptivas, o que não aconteceu com a totalidade das entidades respondentes dos questionários. Em consequência à realização deste estudo, foi possível conhecer mais profundamente a realidade das 
organizações entrevistadas, organizações estas que, embora estejam vinculadas ao mesmo projeto, apresentam estruturas e condições diferentes, o que possibilitou maior riqueza de detalhes na coleta dos dados.

Os entrevistados foram inquiridos acerca da importância das doações, com vistas a criar oportunidade para discorrerem detalhadamente sobre o disclosure e o impacto dessas divulgações nas doações recebidas. Ambos trataram da importância das doações para a perenidade da instituição:

"Elas são fundamentais, porque elas ajudam a manter a própria instituição, nós temos várias despesas . . Então, todas essas doações, elas só vêm para acrescentar a manter e também a ampliar os projetos que a gente faz, as benfeitorias, na manutenção da casa e também auxiliar essas famílias" (E1EA, grifo nosso).

A outra instituição, representada pelo Entrevistado 2 - E2 -, tratou da importância das doações, mas destacou que a entidade se vale muito mais de doações de materiais de consumo, materiais pedagógicos e alimentos que doações em dinheiro, por exemplo, afirmando que a entidade não possui política direta de captação de recursos, mas depende da entidade religiosa mantenedora da organização, além de repasses e recursos de emendas parlamentares.

Independentemente do tipo, os dados coletados nas entrevistas apontam que as doações têm relevância inegável para as entidades sem fins lucrativos. Por isso, os entrevistados foram levados a discorrer sobre a importância da prestação de contas e da divulgação de informações, bem como o possível impacto da prática do disclosure no volume de doações recebidas, e as principais falas que sintetizam essa relação são apresentadas a seguir, confirmando os resultados trazidos por Blouin, Lee e Erickson (2018), onde a divulgação voluntária está fortemente correlacionada com o volume de doações, principalmente se a divulgação for de notícias positivas.

\footnotetext{
“Todos os canais são importantes, porque nós temos doadores que não têm o acesso ainda a todas as mídias... Quanto mais transparente for a instituição, mais facilmente vêm as doações” (E1EA, grifo nosso).

"[Sobre divulgar informações] é uma forma de a gente comprovar perante o CMDCA e o CMAS a existência do projeto e a execução de tudo que a gente alimenta, né" (E2EB).

"Não adianta a pessoa querer trabalhar com 200 crianças e não tem como comprovar, então tudo que a gente faz a gente divulga, a gente registra" (E2EB, grifo nosso).
}

Observa-se, pelo apontado na entrevista E2EB, que o processo de divulgação dessa entidade é bem mais simples, o que, segundo os resultados do estudo de Haski-Leventhal e Foot (2016) é um fator limitador, visto que o volume de doações recebidas aumenta à medida que a entidade investe em marketing e gasta com a captação de recursos e divulgação. A percepção do gestor sobre divulgação, neste caso, limitou-se à divulgação de fotos e trabalhos em um evento específico realizado na entidade, e ao atendimento às exigências legais, denotando pouca preocupação com a accountability pública, resultado também encontrado por Lima (2009), havendo uma carência de divulgação para usuários externos como doadores, por exemplo.

"Nós não temos site. . . Então, assim, a gente tem a página do Face [Facebook, rede social], ela não está atualizada porque não temos um membro mexendo só nela, na verdade acho que a senha está meio que guardada aí. E aí a gente quer ver se reativa o Face" (E2EB, grifo nosso).

"Agora assim, para estar conhecendo [a entidade] em relação a site mesmo, precisava ter, né? (pausa) Uma pessoa mexendo única e exclusivamente para poder abranger isso daí e divulgar mais o nosso trabalho” (E2EB, grifo nosso).

A ausência ou carência de recursos humanos específicos para atuarem na divulgação de informações foi um obstáculo apontado por 30,8\% das entidades respondentes ao questionário, e na entrevista (E2EB) tal desafio é evidenciado por meio dos trechos "não temos um membro mexendo só nela" e "uma pessoa mexendo única e exclusivamente”. A limitação de recursos humanos também remete a um outro obstáculo, apontado por mais de $60 \%$ dos gestores participantes do questionário, que é a restrição ou limitação financeira e orçamentária. Uma das entidades participantes das entrevistas possui website, a outra não, não obstante, ambas reafirmaram a dificuldade de divulgar informações. 
“... porque o site mesmo, para a pessoa construir um site e poder estar atualizando, ele custa, a gente sabe que ele custa. Então, assim, nós temos um técnico de informática” (E2EB, grifo nosso).

"A divulgação tem um custo. . . agora, talvez o pessoal da comunicação teria outras questões, que analisam, às vezes o custo, o profissional, então assim... para abastecer tudo isso, e não são todas as informações que dá para jogar imediatamente" (E1EA, grifo nosso).

A entidade que possui site (EA) explanou sobre como funciona seu processo de divulgação e, dada essa explicação, foi possível identificar a complexidade do processo, que envolve o julgamento de vários setores da organização e o poder discricionário do gestor. Contudo, a complexidade e os custos decorrentes do disclosure, não só no website, mas em vários outros meios de comunicação, são compensados pelos benefícios, pois, segundo o gestor entrevistado, a entidade já provou das vantagens da divulgação, traduzidas pelo aumento de doações, retomando aspectos da taxonomia proposta por Verrecchia (2001).

Outra dificuldade proeminente apontada por um dos gestores como obstáculo à divulgação de informações é a criatividade, conforme apresentado a seguir. Ainda, o entrevistado apresentou razões pelas quais a entidade não divulga todas as informações.

“... não é fácil, nós temos que ter um processo criativo muito grande, porque o site ele não pode ser muito chato, ele tem que ser dinâmico, objetivo, mas atraente" (E1EA).

"Nós temos, claro que não dá para você colocar tudo, às vezes, em um relatório, tudo especificado como um balanço contábil, são muitos detalhes, muita gente não entende também essa questão de fluxo de caixa, entrada, saída, então claro, a gente traz um resumo do que entrou, do que saiu e pronto e foi. Porque também temos que pensar que tem leigos que vão utilizar dessas informações" (E1EA, grifo nosso).

"Nós temos os nossos relatórios em aberto, quem quiser dar uma olhada... nós não temos problema nenhum. Nós temos auditorias, interna e externa, então isso nos dá credibilidade, porque sempre está sendo avaliado a forma com que é gerido os recursos. Agora, é importante sempre mostrar para a sociedade que você está aplicando o dinheiro que ela está dando” (E1EA, grifo nosso).

Desta forma, diante dos níveis de divulgação apresentados em tópico específico, pode-se observar que, embora a maior parte dos respondentes dos questionários, doadores ou gestores, tenham-se mostrado favoráveis à divulgação dos itens componentes do WDI via website, essa prática ainda é deficitária. Vários doadores reconheceram a importância da existência e da alimentação de um website, mas muitos afirmaram não acessar um quando da realização de doações. Ainda, pode-se constatar que poucas foram as doações realizadas via Clique Esperança, embora Campo Grande tenha grande potencial pelo tamanho da cidade.

"Então, assim, eu acho que quando a pessoa procura um escritório de contabilidade, né, para ela fazer essa obrigatoriedade que ela tem com o imposto de renda, o contador já tem quem apresentar [o projeto]" (E2EB, grifo nosso).

Diante desse cenário, pode-se concluir que o aprimoramento desse processo é necessário. Os doadores podem ser mais ativos na busca por informações, as entidades devem ser conscientizadas da importância da prestação de contas e de como os websites podem propiciar a transparência, e embora existam custos associados à divulgação, esses custos são compensados por vários benefícios.

\section{CONSIDERAÇÕES FINAIS}

A prestação de contas representa a externalização, por parte das entidades, das suas ações em prol do cumprimento de sua missão e seus objetivos, com vistas a justificar sua atuação e a utilização dos recursos dispostos em sua responsabilidade. Assim, a divulgação via website pode ser vista como um processo chave na promoção da transparência e na operacionalização da accountability.

Os principais resultados mostram que o nível médio de divulgação de informações gerais é de $56,51 \%$, o de informações contábeis é de apenas 7,69\% e o de informações de desempenho é de 19,23\%. Contudo, $100 \%$ dos doadores e entidades, quando inquiridos, foram unânimes quanto à importância da divulgação de 
8 dos 20 itens componentes do índice, e os percentuais de respondentes que optaram pela não divulgação de determinadas informações é baixo, sugerindo que o potencial dos websites ainda é subutilizado.

Os demais itens, como os referentes às informações contábeis, por exemplo, foram considerados importantes (podendo variar o grau de importância) e dignos de divulgação por, pelo menos, 84,62\% dos respondentes. Não obstante, observa-se que apenas 2, das 26 entidades da amostra pesquisada, disponibilizaram tais itens em seus websites, evidenciando a insuficiência e ineficiência - considerando a última categoria de pesquisa da taxonomia de Verrecchia (2001) - da divulgação viawebsite, pois existe um desalinhamento entre o que o doador espera de informação, o que os gestores consideram importante divulgar e o que efetivamente é disponibilizado pelas entidades.

Dada essa assimetria, fez-se necessário conhecer quais os desafios e obstáculos para a prática do disclosure. Para isso, uma questão aberta foi incluída no questionário, além da realização das entrevistas, que trouxeram como resultados mais frequentes a limitação de recursos financeiros e orçamentários (61,5\%), a limitação com recursos humanos $(30,8 \%)$ e a limitação tecnológica $(15,4 \%)$. Cabe salientar, ainda, que apenas 7,7\% das entidades respondentes afirmaram que os benefícios da divulgação não compensam seus custos.

A limitação financeira e de recursos humanos também foram obstáculos e desafios apontados nas entrevistas e, ainda, outra pontuação foi a questão da criatividade, pois conforme exposto por um dos entrevistados, é difícil saber onde divulgar, o que divulgar, a depender de qual tipo de público atingir, visto que os meios de comunicação são muitos e as informações também, mas é necessário fazer uma ponderação de quais são mais relevantes, até mesmo para buscar a objetividade, dinamicidade e eficiência do disclosure.

Uma preocupação importante trazida por Ingenhoff e Koelling (2009) reforça a importância desse estudo, pois, segundo os autores, a divulgação precisa ser direcionada, de forma que o custo associado à divulgação e prestação de contas não desvie os recursos arrecadados para servir à causa da organização.

Desta forma, fica evidente que as entidades deveriam ser encorajadas, embora não obrigadas, a praticarem o disclosure, intentando serem tão transparentes quanto possível, pois, conforme Blouin, Lee e Erickson (2018), os doadores querem saber se suas doações estão sendo direcionadas para entidades legítimas e se estão sendo bem geridas.

Embora parte significativa dos doadores tenha atribuído alto grau de importância à divulgação de todos os itens do índice de disclosure, grande parte deles afirmaram não acessar o website das entidades quando da realização de uma doação. Suspeita-se que isso aconteça porque esses doadores acham relevante a presença na web, ainda que não se valham do conteúdo disponibilizado, conheçam as entidades pessoalmente ou tenham obtido as informações que consideram importantes por outro meio de comunicação.

Salienta-se que esta pesquisa se limitou às entidades sem fins lucrativos, partícipes do Projeto Clique Esperança e situadas em Campo Grande, capital do estado de Mato Grosso do Sul, e ainda, que a análise dos websites para construção dos índices de divulgação deu-se de maneira estática, ou seja, não houve um acompanhamento para identificar a divulgação progressiva de informações pelas entidades. Sugere-se que em pesquisas futuras seja realizado um acompanhamento dinâmico dos níveis de divulgação, analisando possíveis associações com as doações recebidas.

\section{Agradecimentos}

O presente trabalho foi realizado com apoio da Coordenação de Aperfeiçoamento de Pessoal de Nível Superior - Brasil (CAPES) - Código de Financiamento 001.

\section{REFERENNCIAS}

Blouin, M. C., Lee, R. L., \& Erickson, G. S. (2018). The impact of online financial disclosure and donations in nonprofits. Journal of Nonprofit \& Public Sector Marketing, 30(3), pp. 251-266. 
Botosan, C. A. (2006) Disclosure and the cost of capital: what do we know? Accounting and Business Research, United Kingdom, 36(sup1), pp. 31-40.

Collis, J.; \& Hussey, R. (2005). Pesquisa em administração: um guia prático para alunos de graduação e pós-graduação. (2. Ed). Porto Alegre: Bookman.

Conselho Federal de Contabilidade. (2015). ITG 2002 (R1): Entidade sem finalidade de lucros. Recuperado em 14 março, 2019, de http://www1.cfc.org.br/sisweb/sre/detalhes_sre.aspx?Codigo=2015/ITG2002(R1).

Conselho Federal de Contabilidade. (2017). NBC TG 26 (R5): apresentação das demonstrações contábeis. Recuperado em 14 março, 2019, de http://www1.cfc.org.br/sisweb/SRE/docs/NBCTG26(R5).pdf.

Consoni, S., Colauto, R. D., \& Lima, G. A. S. F. (2017) Voluntary disclosure and earnings management: evidence from the Brazilian capital market. Revista Contabilidade \& Finanças, 28(74), pp. 249-263.

Creswell, J. W. (2007). Projeto de pesquisa: métodos qualitativo, quantitativo e misto. (2. ed.) Porto Alegre: Artmed.

Cruz, C. V. O. A. (2010). A relevância da informação contábil para os investidores sociais privados de entidades do terceiro setor no Brasil: uma investigação empírica. Tese de Doutorado, Universidade de São Paulo, São Paulo, SP, Brasil.

Deng, G., Lu, S., \& Huang, C. (2015). Transparency of grassroots human service organizations in China: does transparency affect donation and grants? Human Service Organizations: Management, Leadership \& Governance, 39(5), pp. 475-491.

Dye, R. A. (2001). An evaluation of "'essays on disclosure" and the disclosure literature in accounting. Journal of Accounting and Economics, Netherlands, 32(1-3), pp. 181-235.

Gandía, J. L. (2011). Internet disclosure by nonprofit organizations: empirical evidence of nongovernmental organizations for development in Spain. Nonprofit and Voluntary Sector Quarterly, 40(1), pp. 57-78.

Guidry, R. P.; \& Patten, D. M. (2012). Voluntary disclosure theory and financial control variables: an assessment of recent environmental disclosure research. Accounting Forum, 36(2), pp. 81-90.

Haski-Leventhal, D.; \& Foot, C. (2016). The relationship between disclosure and household donations to nonprofit organizations in Australia. Nonprofit and Voluntary Sector Quarterly, 45(5), pp. 992-1012.

Healy, P. M.; Palepu, K. G. (2001). Information asymmetry, corporate disclosure and the capital markets: a review of the empirical disclosure literature. Journal of Accountancy and Economics, 31(1-3), pp. 405-440.

Ingenhoff, D.; \& Koelling, A. M. (2009). The potential of Web sites as a relationship building tool for charitable fundraising NPOs. Public Relations Review, 35(1), pp. 66-73.

Lee, R. L.; \& Blouin, M. C. (2017). Factors affecting web disclosure adoption in the nonprofit sector. Journal of Computer Information Systems, 59(4), pp. 363-372.

Lima, E. M. (2009). Análise comparativa entre o índice de disclosure e a importância atribuída por stakeholders a informações consideradas relevantes para fins de divulgação em instituições de ensino superior filantrópicas no Brasil: uma abordagem da teoria da divulgação. Tese de Doutorado, Universidade de São Paulo, São Paulo, SP, Brasil.

Lima, E. M.; \& Pereira, C. A. (2011). Associação entre índices de disclosure e características corporativas das Instituições de Ensino Superior Filantrópicas do Brasil-IESFB. Revista de Contabilidade e Organizações, 5(11), pp. 23-48.

Parsons, L. M. (2007). The Impact of financial information and voluntary disclosures on contributions to not-forprofit organizations. Behavioral Research In Accounting, 19(1), pp. 179-196.

Salotti, B. M.; \& Yamamoto, M. M. (2005). Ensaio sobre a teoria da divulgação. BBR Brazilian Business Review, 2(1), pp. 53-70.

Saxton, G. D., Kuo, J. S., \& Ho, Y. C. (2012) The determinants of voluntary financial disclosure by nonprofit organizations. Nonprofit and Voluntary Sector Quarterly, 41(6), pp. 1051-1071.

Saxton, G. D., Neely, D. G., \& Guo, C. (2014). Web disclosure and the market for charitable contributions. Journal of Accounting and Public Policy, 33(2), pp. 127-144. 
Laísa Aparecida Pereira de Souza, et al. Divulgar para quê? Índice de disclosure e a importância A...

Saxton, G. D.; \& Zhuang, J. (2013). A game-theoretic model of disclosure-donation interactions in the market for charitable contributions. Journal of Applied Communication Research, USA, 41(1), pp. 40-63.

Verrecchia, R. E. (1983). Discretionary disclosure. Journal of Accounting and Economics, 5, pp. 179-194.

Verrecchia, R. E. (2001). Essays on disclosure. Journal of Accounting and Economics, Amsterdam, 32(1-3), pp. 97-180.

Waters, R. D. (2007). Nonprofit organizations' use of the internet: a content analysis of communication trends on the internet sites of the philanthropy. Nonprofit Management and Leadership, 18(1), pp. 59-76. 